\title{
Achievements in development of prenatal diagnostics in republic of Kazakhstan
}

\author{
Zhanar Kurmangali1, [Kulyash Dzhamanaeva] ${ }^{2}$, Fred Ushakov ${ }^{3}$, Talshyn Ukybasova ${ }^{2}$, Almash Bekmuhametova ${ }^{1}$,
} Aigul Sopbekova ${ }^{1}$, Dias Saidangazin ${ }^{1}$

${ }^{1}$ Republican diagnostic center of the corporate fund "UMC», Astana, Kazakhstan

${ }^{2}$ National research center for maternal and child health of the corporate fund "UMC», Astana, Kazakhstan

${ }^{3}$ University College London Hospital,London, UK

\section{ABSTRACT}

This article presents the results of the three-year experience of the Fetal Medicine Center. For this period, non-invasive (20 911) and invasive methods of prenatal diagnosis (3 031) were conducted, aimed at early detection of congenital malformations and chromosomal abnormalities of the fetus, complications of pregnancy. In addition, it proposed a number of other important achievements of the Center Fetal Medicine in the field of prenatal diagnosis in the country.

Key words: Fetal medicine center, prenatal diagnosis, congenital developmental malformation, chromosomal abnormalities.

\section{ТҰЖЫРЫМДАМА}

ҚАЗАҚСТАН РЕСПУБЛИКАСЫНДАҒЫ ПРЕНАТАЛДЫҚ ДИАГНОСТИКАНЫН ДАМУ ЖЕТІСТІКТЕРІ

Құрманғали Ж.Қ.' ${ }^{1}$ [Джаманаева К.Б.] ${ }^{2}$, Ushakov F. ${ }^{3}$, Үкібасова T.М. ${ }^{2}$, Бекмухаметова А.А. ${ }^{1}$, Сопбекова А.К. ${ }^{1}$, Сайдангазин Д. Д. ${ }^{1}$

'«UMC» корпоративтік қорының Республикалық диагностикалық орталығы, Астана, Қазақстан ${ }^{2}$ «UMC» корпоративтік қорының Ана мен бала ұлттық ғылыми орталығы, Астана, Қазақстан ${ }^{3}$ University College London Hospital, London, UK.

Ұсынылған мақалада ұрық медицинасы Орталығының үш жылдық жұмыс тәжірибесінің нәтижесі көрсетілген. Осы көрсетліген мерзімде тума ақаулар мен хромосомдық ауруларды, жүктілік ағымының асқынуларын еретерек анықтау мақсатында пренаталдық диагностиканың инвазиялық (3 031) және инвазиялық емес (20 911) әдістері қолданылғаны жайлы айтылған. Сонымен қатар, ұрық медицинасы Орталығы жұмысында ресубликада қолданылған пренаталдық диагностика аумағындағы бірқатар маңызды жетістіктері де ұсынылған.

Маңызды сөздер: ұрық медицинасы Орталығы, пренаталдық диагностика, тума ақаулар, хромосомдық аномалиялар

PЕЗЮME

ДОСТИЖЕНИЯ В ОБЛАСТИ РАЗВИТИЯ ПРЕНАТАЛЬНОЙ ДИАГНОСТИКИ В РЕСПУБЛИКЕ КАЗАХСТАН

Курмангали Ж.К. ${ }^{1}$, [Джаманаева К.Б.] ${ }^{2}$, UshakovF. ${ }^{3}$, Укыбасова T.M. ${ }^{2}$, Бекмухаметова А.А.' ${ }^{1}$ Сопбекова А.К.1, Сайдангазин Д.Д. ${ }^{1}$

'Республиканский диагностический центр корпоративного фонда «UMC», Астана, Казахстан ${ }^{2}$ Национальный научный центр материнства и детства корпоративного фонда «UMC», г. Астана, Казахстан ${ }^{3}$ UniversityCollegeLondonHospital, London, UK.

В данной статье представлены результаты трехлетнего опыта работы Центра медицины плода. За указанный период были проведены неивазивные (20 911) и инвазивные методы пренатальной диагностики (3 031), направленные на раннее выявление врожденных пороков развития и хромосомных аномалий плода, а также осложнений течения беременности. Кроме того, предложены ряд других важных достижений деятельности Центра медицины плода в области пренатальной диагностики в республике.

Ключевые слова: Центр медицины плода, пренатальная диагностика,врожденные пороки развития, хромосомные аномалии

\section{Введение}

По решению Правления Акционерного Общества «Национальный научный центр материнства и детства» и Медицинского Холдинга, г.Астана 8 сентября 2014 года был открыт Центр медицины плода. Его организация была вызвана острой необходимостью оказания высокотехнологичных медицинских услуг в области пренатальной диагностики, профилактики и лечения врожденных пороков развития (ВПР) и заболеваний плода, а также акушерских осложнений в целях улучшения исходов для матери и плода в суверенном Казахстане. Согласно статистическим данным в Республике Казахстан частота врожденных аномалий (пороков развития), деформаций и хромосомных нарушений составляет 710.8 на 100000 человек населения [1].

Надо отметить, что в республике медицинские услуги в области пренатальной диагностики были разрознены и не систематизированы. Однако, благодаря политике Елбасы, 
была получена возможность обучения новейшем методам диагностики и лечения в лучших зарубежных клиниках. В частности, текущая деятельность Центрамедицины плода основана на международном опыте ведения различных патологий плода в аналогичном Центре UniversityCollegeLondonHospital (Великобритания).

Медицина плода в Республике Казахстан сегодня это - экспертный уровень оказания медицинских услуг беременным женщинам на основе использования международных стандартов, программ и руководств, предложенных профессиональными организациями Западной Европы и США (Ultrasoundscreeningforfetalabnormalities. Report of the RCOG Working Party. London: The Royal College of Obstetricians and Gynaecologists; Fetal Medicine Foundation; American College of Obstetricians and Gynecologists)[2-14].

Таким образом, за три года существования Центра медицина плода были достигнуты следующие результаты:

-сформирована новейшая современная структурированная система по решению исследуемых проблем;

-проводятся инвазивные диагностические процедуры (биопсия хориона, плацентоцентез, кордоцентез) для определения кариотипа плода в целях исключения хромосомных и генетических заболеваний;

- используются неинвазивные методы пренатальной диагностики аномалий развития плода;

-внедренысовременные, новыевиды медицинских услуг;

- внедрены трансферт технологии:

- неинвазивный пренатальныйтест (NIPT) с использованием метода rMPS (Random Massively Parallel Sequencing - Высокопроизводительное параллельноесеквенирование) диагностикиразличных видов хромосомных аномалий у плода с I триместра беременности;

-методы ранней диагностики пороков развития центральной нервной системы, сердца плода;

-действует мультидисциплинарный консилиумврачейконсультантов различных специальностей (акушергинеколог, неонатальный хирург, детский кардиохирург, нейрохирург, невролог, уролог, челюстно-лицевой хирург, генетик, инфекционист и др.), направленныйдля решения вопроса возможности пролонгирования или прерывания беременности, определения тактики ведения беременности, оптимального метода и срока родоразрешения;

- оказывается стационарзамещающая помощь пациентам при различных осложнениях течения беременности.

Хотелось бы отметить, что работа Центра медицины плода направлена на улучшение исходов в масштабах всей республики.

Центр медицины плода оснащен современным диагностическим оборудованием, в котором работают высококвалифицированные специалисты.

За три года работы (2014-2017гг) Центра медицины плода было проведено 20911 ультразвуковых, допплерометрических и кардиотокографических (КТГ) исследований (Таблица 1).

Анализ проведенных исследований показал, что за период работы Центра медицины плода первично были обследованы и консультированы 263 беременных женщин с подозрением на различные ВПР плода. Из них в 147 (55,9\%) случаях ранее выявленные патологии плода получили
Таблища 1 Общее количество проведенных медицинских услуг в Центре медицины плода

\begin{tabular}{|l|l|l|l|}
\hline № & Наименование услуг & & \\
\hline & Количество проведенных услуг & & \\
\hline 1 & $\begin{array}{l}\text { Ультразвуковое, допплерометриче- } \\
\text { ское исследование }\end{array}$ & Абс. число & $\%$ \\
\hline & 83,2 & 405 & \\
\hline 2 & Автоматизированная КТГ плода & 3506 & 16,8 \\
\hline & Всего & 20911 & 100 \\
\hline
\end{tabular}

подтверждение, в 37 (14,1\%) случаях были опровергнуты, в 79 (30\%) наблюдениях были диагностированы впервые.

В структуре выявленных аномалий плода (всего 243100\%) преобладали врожденные пороки сердца (91-37,4\%), мочевыводящих путей (57-23,5\%), центральной нервной системы (33-13,6\%), также обнаружены пороки развития желудочно-кишечного тракта (14-5,8\%), множественные ВПР (22-9,0\%) и другие аномалии (26-10,7\%).

Нарушения функционального состояния плода по данным допплерометрического и КТГ исследований были установлены у 207 пациенток.

За период работы Центра медицины плода общее количество выполненных различных видов инвазивных диагностических процедур беременным женщинам составило 3 031. В условиях дневного стационара в953случаях были проведены лечение осложнений течения беременности (Таблица 2).

\section{Таблица 2 Спектр оказанных медицинских услуг в} Центре медицины плода

\begin{tabular}{|c|c|c|c|}
\hline № & $\begin{array}{l}\text { Суммарный спектр оказанных медицинских } \\
\text { услуг }\end{array}$ & Абс. число & $\%$ \\
\hline I & \multirow{2}{*}{$\begin{array}{l}\text { Диагностика ВПР плода } \\
\text { Сердечно-сосудистой системы }\end{array}$} & \multirow[t]{2}{*}{91} & \multirow[t]{2}{*}{37,4} \\
\hline \multirow[t]{7}{*}{ - } & & & \\
\hline & • Мочеполовой системы & 57 & 23,5 \\
\hline & •Центральной нервной системы & 33 & 13,6 \\
\hline & •Желудочно-кишечного тракта & 14 & 5,8 \\
\hline & •Множественные ВПР & 22 & 9,0 \\
\hline & •Другие & 26 & 10,7 \\
\hline & Всего & 243 & 100 \\
\hline \multirow[t]{5}{*}{ II } & \multirow{2}{*}{$\begin{array}{l}\text { Инвазивные диагностические процедуры } \\
\text { • Биопсия хориона }\end{array}$} & \multirow[t]{2}{*}{276} & \multirow[t]{2}{*}{9,1} \\
\hline & & & \\
\hline & •Плацентоцентез & 1271 & 41,9 \\
\hline & •Кордоцентез & 1484 & 49 \\
\hline & Всего & 3031 & 100 \\
\hline \multirow[t]{7}{*}{ III } & \multirow{2}{*}{$\begin{array}{l}\text { Стационар замещающая помощь } \\
\text { • Ранний токсикоз }\end{array}$} & \multirow[t]{2}{*}{522} & \multirow[t]{2}{*}{54,8} \\
\hline & & & \\
\hline & $\begin{array}{l}\text { •Угроза прерывания } \\
\text { беременности }\end{array}$ & 313 & 32,9 \\
\hline & •Анемия & 49 & 5,1 \\
\hline & •Пиелонефрит & 20 & 2,1 \\
\hline & $\begin{array}{l}\text { •Медикаментозное прерывание беремен- } \\
\text { ности }\end{array}$ & 49 & 5,1 \\
\hline & Всего & 953 & 100 \\
\hline \multirow[t]{9}{*}{ IV } & \multirow{2}{*}{$\begin{array}{l}\text { •Консультирование врачами-консультан- } \\
\text { тами } \\
\text { •Детский уролог }\end{array}$} & \multirow[t]{2}{*}{5,7} & \multirow[t]{2}{*}{65} \\
\hline & & & \\
\hline & •Детский кардиохирург & 114 & 9,9 \\
\hline & •Детский хирург & 50 & 4,3 \\
\hline & •Детский нейрохирург & 27 & 2,3 \\
\hline & •Генетик & 849 & 74 \\
\hline & •Детский челюстно-лицевой хирург & 8 & 0,7 \\
\hline & •Другие & 35 & 3,1 \\
\hline & Всего & 1148 & 100 \\
\hline
\end{tabular}


Вместе с клинической работой, Центр медицины плода также проводит образовательную деятельность $[15$, 16]. За указанный период проведены мастер-классы с привлечением ведущих зарубежных специалистов, курсы повышения квалификации, подготовка резидентов-стажеров I-III года обучения по специальности «Акушерство и гинекология»(Таблица 3).

Таблица 2 Образовательные мероприятия на базе Центра медицины плода

\begin{tabular}{|c|c|c|}
\hline № & Образовательные мероприятия & Вид обучения \\
\hline 1 & $\begin{array}{l}\text { «Ультразвуковая диагностика и } \\
\text { Фетальная медицина»03-07 декабря } \\
2013 \text { г }\end{array}$ & $\begin{array}{l}\text { Международный мастер- } \\
\text { класс }\end{array}$ \\
\hline 2 & $\begin{array}{l}\text { «етальная эхокардиография» совместно } \\
\text { с врачами АО «Национальный научный } \\
\text { кардиохирургический центр»14-25 июля } \\
2014 \text { года }\end{array}$ & $\begin{array}{l}\text { Международный мастер- } \\
\text { класс }\end{array}$ \\
\hline 3 & $\begin{array}{l}\text { «Вопросы создания Центра Медицины } \\
\text { Плода. Диагностика врожденных пороков } \\
\text { развития Центральной нервной системы } \\
\text { плода» 6-10 октября 2014г }\end{array}$ & $\begin{array}{l}\text { Международный мастер- } \\
\text { класс }\end{array}$ \\
\hline 4 & $\begin{array}{l}\text { «Современные достижения } \\
\text { ультразвуковой диагностики } \\
\text { врожденных пороков развития грудной } \\
\text { клетки, брюшной полости и мочеполовой } \\
\text { системы плода» 14-18 декабря 2015г }\end{array}$ & $\begin{array}{l}\text { Международный мастер- } \\
\text { класс }\end{array}$ \\
\hline 5 & $\begin{array}{l}\text { «Способ ранней ультразвуковой } \\
\text { диагностики врожденных пороков } \\
\text { развития грудной клетки, брюшной } \\
\text { полости и мочеполовой системы плода с I } \\
\text { триместра беременности» декабрь 2015г }\end{array}$ & Акт внедрения \\
\hline 6 & $\begin{array}{l}\text { «Использование 3-4D ультразвуковых } \\
\text { технологий в диагностике ВПР плода» } \\
\text { 03-07 июля 2017г }\end{array}$ & $\begin{array}{l}\text { Международный мастер- } \\
\text { класс }\end{array}$ \\
\hline 7 & $\begin{array}{l}\text { «Правила оказания услуг нейросо- } \\
\text { нографии плода в I-III триместрах } \\
\text { беременности»,август 2017г }\end{array}$ & $\begin{array}{l}\text { Стандарт операционной } \\
\text { процедуры оказания услуги }\end{array}$ \\
\hline 8 & $\begin{array}{l}\text { «Правила оказания услуг кардиотокогра- } \\
\text { фии плода», июль } 2016 \text { г }\end{array}$ & $\begin{array}{l}\text { Стандарт операционной } \\
\text { процедуры оказания услуги }\end{array}$ \\
\hline 9 & $\begin{array}{l}\text { «Правила оказания услуг стационароза- } \\
\text { мещающей помощи», июль } 2016 г\end{array}$ & $\begin{array}{l}\text { Стандарт операционной } \\
\text { процедуры оказания услуги }\end{array}$ \\
\hline 10 & $\begin{array}{l}\text { Внедрение и использование новой мето- } \\
\text { дики трансферт-технологии проведения } \\
\text { расширенной нейросонографии плода в } \\
\text { I-ІІІ триместрах беременности согласно } \\
\text { опубликованным данным (T. Loureiro, } \\
\text { F. Ushakov, N. Montenegro, Y. Gielchinsky, } \\
\text { K. H. Nicolaides. Cerebral ventricular } \\
\text { system in fetuses with open spina bifida at } \\
\text { 11-13 weeks' gestation. J. UltrasoundObstet. } \\
\text { Gynecol. 2012; 39: 620-624),август 2017г }\end{array}$ & $\begin{array}{l}\text { Протокол расширенной } \\
\text { нейросонографии плода в } \\
\text { I-III триместрах беремен- } \\
\text { ности }\end{array}$ \\
\hline 11 & $\begin{array}{l}\text { «Способ ультразвуковой диагностики } \\
\text { врожденных пороков развития головного } \\
\text { мозга плода вI-ІІІ триместрах беременно- } \\
\text { сти», август 2017г }\end{array}$ & Акт внедрения \\
\hline 12 & $\begin{array}{l}\text { «Допплерография в акушерстве» 108час, } \\
\text { 2014-2017гг }\end{array}$ & $\begin{array}{l}\text { Цикл повышения квали- } \\
\text { фикации }\end{array}$ \\
\hline 13 & $\begin{array}{l}\text { «Кардиотокография плода в современном } \\
\text { акушерстве» } 108 \text { час, 2014-2017гг }\end{array}$ & $\begin{array}{l}\text { Цикл повышения квали- } \\
\text { фикации }\end{array}$ \\
\hline 14 & $\begin{array}{l}\text { «Актуальные вопросы ультразвуковой } \\
\text { диагностики в акушерско-гинекологиче- } \\
\text { ской практике» 80час, 2015г }\end{array}$ & $\begin{array}{l}\text { Стажировка на рабочем } \\
\text { месте }\end{array}$ \\
\hline \multicolumn{3}{|l|}{15} \\
\hline & $\begin{array}{l}\text { Цикл повышения квалификации «Не- } \\
\text { вынашивание беременности» 108час, } \\
\text { 2014-2016гг }\end{array}$ & \\
\hline & $\begin{array}{l}\text { Участие в цикле повышения квалифи- } \\
\text { кации }\end{array}$ & \\
\hline 16 & $\begin{array}{l}\text { «Пренатальная диагностика врожденных } \\
\text { пороков развития и наследственных за- } \\
\text { болеваний» 108час, 2014-2017гг } \\
\end{array}$ & $\begin{array}{l}\text { Участие в цикле повыше- } \\
\text { ния квалификации }\end{array}$ \\
\hline \multirow[t]{2}{*}{17} & $\begin{array}{l}\text { Специальность «Акушерство и гинеколо- } \\
\text { гия», 2014-2017гг }\end{array}$ & \\
\hline & Кураторство резидентов-стажеров & \\
\hline 18 & $\begin{array}{l}\text { «Ультразвуковое сканирование. Доппле- } \\
\text { рометрические исследования кровотока } \\
\text { в системе мать-плацента-плод», «Методы } \\
\text { исследования околоплодных вод», «Кар- } \\
\text { диотокографияплода», 2014-2017гг }\end{array}$ & $\begin{array}{l}\text { Лекции для резидентов- } \\
\text { стажеров }\end{array}$ \\
\hline
\end{tabular}

В Республиканском диагностическом центре Корпоративного Фонда «University MedicalCenter»г.Астана функционирует единственный в Казахстане Центр медицины плода, который является аналогичным центром зарубежной практики и третьим центром подобного направления на территории Содружества Независимых Государств (Москва, Санкт-Петербург).Основным направлением деятельности Центра является ранняя диагностика и профилактика врожденных пороков развития и заболеваний плода, а также акушерских осложнений в целях улучшения исходов для матери и плода. Центр медицины плода является базой для проведения научно-исследовательских работ, а также учебной базой для подготовки специалистов.

В перспективе планируется дальнейшее развитие данного направления в медицине, внедрение современных трансферттехнологий,разработкаивнедрениеновых методов диагностики, профилактики и лечения ВПР и заболеваний плода в клиническую практику, образовательных программ профессиональной подготовки медицинских сотрудников путем участия в курсах повышения квалификации, мастерклассах, семинарах, конференциях, практическом тренинге. 


\section{Литература:}

1. Health of the population of Republic of Kazakhstan and the activities of health organizations in 2015 [in Russian]. Statistical collection. Astana: Medinform LLP; 2016. 358 p.

2. Organization of prenatal screening [in Russian]. Order of the Minister of Health Republic Kazakhstan from September 09, 2010 №704. Retrieved from https://adilet.zan.kz/rus/docs/V1000006490.

3. International Society of Ultrasound in Obstetrics and Gynecology. Cardiac screening examination of the fetus: guidelines for performing the "basic" and "extended basic" cardiac scan. J Ultrasound Obstet Gynecol.2006;27:107-13.

4. Guidelines for the First Trimester Screening program. The Fetal Medicine Foundation. United Kingdom; 2008. 20 p.

5. ISUOG Practice Guidelines: Sonographic examination of the fetal central nervous system. J Ultrasound Obstet Gynecol.2007;29:109-16.

6. ISUOG Practice Guidelines (updated): Sonographic screening examination of the fetal heart. J Ultrasound Obstet Gynecol.2013;41:348-59.

7. ISUOG Practice Guidelines: Performance of first trimester fetal ultrasound scan. J Ultrasound Obstet Gynecol. 2013;41:102-13.

8. ISUOG Practice Guidelines: Use of Doppler ultrasonography in obstetrics. J Ultrasound Obstet Gynecol.2013;41:233-9.

9. American College of Obstetricians and Gynecologists. (2007a). Practice bulletin №77: screening for fetal chromosomal abnormalities. J Obstetrics and Gynecology.2007;109:217-7.

10. American College of Obstetricians and Gynecologists. (2007b). Practice bulletin №88: invasive prenatal testing for aneuploidy.J Obstetrics and Gynecology.2007;110:1459-67.

11. American College of Obstetricians and Gynecologists (2009). Practice bulletin №101: ultrasonography in pregnancy.J Obstetrics and Gynecology.2009;113:451-61.

12. ACOG Committee on Practice Bulletins. ACOG Practice Bulletin No. 77: screening for fetal chromosomal abnormalities.J Obstetrics and Gynecology.2007; 109:217-27.

13. NHS Fetal Anomaly Screening Programme $-18+0-20+6$ week fetal anomaly scan. Guidance. NHS public health functions agreement 2016-17,from February 05, 2016; 33 p.

14. Ward P, Soothill P. Fetal anomaly ultrasound scanning: the development of a national programme for England. The Obstetrician \&Gynaecologist. 2011;13:211-7.

15. On the approval of the Standards of Operational Procedures in the Department of Fetal Medicine and the Department of Management of Pregnant Women's Health Center [in Russian]. Order of the director of the branch of the CF "UMC, from July 15, 2016 №84-e.

16. Loureiro T., Ushakov F., Montenegro N., Gielchinsky Y., Nicolaides KH. Cerebral ventricular system in fetuses with open spina bifida at 11-13 weeks' gestation. J Ultrasound Obstet Gynecol. 2012; 39(6):620-4. 